\title{
НАПРАВЛЕНИЯ ТРАНСФОРМАЦИИ ЛОКАЛЬНОСТИ В ПОСТИНДУСТРИАЛИЗМЕ ДЛЯ СООБЩЕСТВ
}

\section{TRENDS OF THE TRANSFORMATION OF LOCALITY FOR COMMUNITIES IN POST-INDUSTRIALISM}

\section{E. Orekhovskaya}

Summary: Local communities and changes to them due to the development of post-industrialism will be explored in the article. The shift base constants of communities are noted by many researchers, such as a locality, enduring ties based on a long duration face-to-face contact; a personal interaction offline, a switching to virtual space. The analysis is based on drawing parallels with the principle of nonlocality considered in quantum physics.

Keywords: non-locality, alocality, local communities, dislocal communities, transformation of local communities, trends, PostIndustrialism.

\author{
Ореховская Евгения Владимировна \\ соискатель, Кемеровский государственный \\ университет, г. Кемерово \\ yamantaka.j@yandex.ru
}

Аннотация: В статье будет сделана попытка объяснить изменения, происходящие с локальными сообществами в постиндустриальную эпоху, в результате которых они теряют основные свои константы, в первую очередь такие, как собственно локальность, прочные, устойчивые связи, основанные на долговременном контакте лицом-к-лицу, само общение лицом-к-лицу, распространение в пространство виртуальное и перенос в него коммуникации. Анализ строится на проведении параллелей спринципом нелокальности, рассматриваемой в квантовой физике.

Ключевые слова: нелокальность, алокальность, локальные сообщества, дислокальные сообщества, трансформация локальных сообществ, тенденции, постиндустриализм.
$\mathrm{O}$ дной из важных социально-философских тем для исследования являются существование локальных сообществ. Тем более актуальны такие исследования в момент перехода к постиндустриализму, в период массированного развития коммуникаций, Интернета с образованием всевозможных групп социальных сетей, сетевых сообществ, одновременно с усложняющейся динамикой социальной жизни и ускоренным развитием транспортного сообщения. Все это приводит к уменьшению значимости отдельно взятой локальности и её роли в огромных мегаполисах.

В работе при исследовании изменения сообщества мы будем опираться на теорию сетевого общества Мануэля Кастельса и Ян ван Дейка; перераспределение локальности с помощью акторно-сетевой теории Бруно Латура. При исследовании возможности применения определения нелокальности к сообществам применим методику Георгия Федоровича Миронова, философа Ульяновского университета, в трудах которого раскрывается применение понятий локальности и нелокальности как онтологическая проблема [9]. В исследовании постиндустриализма важно мнение российского философа Т.Х. Керимова, который утверждал, что применение редукционистских терминов «согласно принципам субстантивизма» [5, с.16] не позволят цельно объяснить протекающие в постиндустриализме социальные процессы [5, с.26-27], характеризующиеся комплексностью, но правильными будет обратиться к различным теориям, взятым в их совместной интеграции, то есть мезоредукционизму [там же]. Объяснение нелокальности основано на идеях квантовой физики, выявленных Энштейном [12].

Классическое определение локального сообщества характеризуются двойственностью в описании его природы: либо как пространство, связывающее индивидов с географическим регионом, либо как аттрактор, построенный на общности связей, желаний, общих черт или общих интересов, (см. Минар и Грир, 1969)» [15; 17, c.670]. Современный философ В.Е. Кемеров указывал, что для рассмотрения динамики преобразований локальных сообществ и перспектив их развития необходимо обращаться к трансформачионной модели, которая учитывает, как изменяется пространственный фактор. Эта модель вскрывает проблематику изменений сообществ, которые реализуются «не только в пространстве, но и во времени» [4].

Способ объединения индивидов в сообщества «по принципам разделенной во времени и пространстве деятельности» [там же], а не по принципу совместности стал фиксироваться ещё начиная с 60-х годов XX века, совпадая по времени появления с началом появления активных теоретических разработок теории постиндустриализма. Здесь мы видим сдвиг двух, или даже трех параметров: разделение во времени, отход от единства пространства, и доминанта деятельности. В таком случае «клеем» сообщества оказывается не пространство и не место, а деятельность с ее задачами, программами, 
целями и результатами [там же]. Сообщества, построенные на таких основах, то есть имеющие общий аттрактор, становятся преобладающими в последнее время. Наблюдаются такие явления не только в развитых мегаполисах мира, но и фиксируется в других местах. В работах одного из классиков постиндустриальной теории, делавшего упор на информатизацию и сетевой характер социальных структур - М. Кастельса с опорой на мнение таких ученых, как Фишер (1982), Эспиноза (1999), Перльман (2002) указывается, что «фактор географической близости утратил свою значимость в структурировании общественных связей во многих из этих пораженных нищетой регионах, по крайней мере, еще четверть века тому назад» [3]. Место уступает в значении потокам, о чем писал и Латур, и Кастельс в своих трудах по исследованию сетевого общества, но тем не менее, определение локальности в существующей тематике исследований сообществ остаются актуальными.

Одновременно ряд ученых утверждают о замещении параметра локальности в современном мире. Основоположник постиндустриальной теории Р. Патнем определил в качестве ведущего фактора в определении сообщества наличие у его членов сильных внутригрупповых связей (Putnam, 2000) [14], а не территориальную близость. Так, В. Вахштайн продолжил исследования определив, что на смену традиционному пониманию приходит локальное сообщество как универсальная категория социологического мышления [1, с.15-16]. И.В. Вахштайн, и В.Е. Лебедева определяют в современном сообществе функцию «от индивидов и территории» [1; 7]

В дальнейшем переход локальности рассматривался нами в статье «Трансформация определения термина "локальное сообщество"» [11], а так же современным российским исследователем А. Скуратовым [13]. Основная мысль этих исследований приводит к выводу о смещении локальности во вне-локальную плоскость и перенесения процесса социального взаимодействия в плоскость коммуникаций.

На основании приведенных аргументов мы можем сделать вывод, что в постиндустриальном обществе само понятие локального сообщества становится под вопросом. Либо сообщество перестает быть локальным, так как локация теряет привязку к конкретному месту: топосу либо хору, либо сама формулировка нуждается в корректировке и уточнении.

Собственно локальность как признак, характеризующий сообщества, перестает в постиндустриализме быть определяющим и становится скорее следствием. Ведущим признаком становится не место, а повод, идея, смысл и действие. Осуществленное в том числе с помо- щью медиасетей объединение индивидов в сообщество самостоятельно решает, нужно ли собираться вместе в едином пространстве, либо ограничиваться общением виртуальным. Это соответствует так же характеристикам, изложенным Дейком в своей концепции сетевого общества, в которой он признавал, что социальные отношения лицом-к-лицу постепенно переходят в отношения в медиасетях, либо дополняются ими [18].

И в эту тенденцию уже сейчас вторгаются непредвиденные факторы, которые ещё более усугубляют положение традиционных локальных сообществ: запрещение, или ограничение на физические контакты и сбор коллективов одновременно вместе признается небезопасным с эпидемиологической точки зрения. ${ }^{1}$ Если такие меры будут продолжены, они будут чреваты утратой связей офлайн, в реальной жизни, и форсированным замещением их виртуальной коммуникацией. Более того, долговременная практика стереотипных событий, длящаяся больше года, вырабатывает эффект «обычности», который встроится в сознание людей как «нормальное» положение, и в результате сам возврат к традиционному общению для части индивидов может показаться странным и ненужным. Но, тем не менее, остаются общие дела, ради которых необходимо собираться вместе, чтобы осуществить действие. Не просто собраться, но выполнить задачу. Как правило, это действие носит добровольческий характер и имеет экологическую направленность, а также выражается в виде помощи людям, животным и природе в целом.

В концепциях сообщества это можно представить как транзит от принципа от экстериорности отношения к принципу событийности, что лучше представлено по мнению Т.Х. Керимова, в антиредукционистской, онтологической традиции [5, с.16]. Здесь мы вплотную подходим к сдвигу локальности. Сообщества трансформируются в сети, что было впервые замечено ещё Барри Уэллманом: «сообщества - это сети межличностных связей, обеспечивающие социальное взаимодействие, поддержку, информацию, чувство принадлежности к группе и социальную идентичность» и дополнено М. Кастельсом, который уточнил формулировку, обозначив, что основной формой организации взаимодействия в сообществе становится сеть [3]. Так, от контактов лицомк-лицу, характерных для традиционного локального сообщества, происходит переход к сети взаимодействий. Основная часть этих взаимодействий осуществляется в данный момент, в глобальной сети Интернет.

Изменения локальности в понимании Б. Латура выражается в смене доминанты локального взаимодействия в сторону с связей, средств передвижения и соединений. Места при этом, как и любое локальное взаимодействие

1 По ситуации март-июнь, и октябрь-ноябрь 2020 года. 
при увеличении дистанции трансформируются в акторсети [6, с.237, 267, 305-307]. На первый план выходят потоки. Кастельс в своей теории отстаивает мысль, что пространство потоков обрывает связи с привычным местом, уничтожая само пространство, которое напоминает скорее стремительный поток энергии. Таким образом, создаваемые потоки отрывают от корней и втягивают людей в новые места, не имеющие привычных координат. На смену «месту» приходит «безместье», о чем хорошо было описано у Т. Рельф: «Антоним «безместье» маркирует негативные последствия глобализации и унификации мира» и следуя за этой трансформацией, локальные сообщества теряют локальность, становясь нелокальными [16].

Чтобы разобраться с изменчивостью локальности, обратимся к мнению физиков. Если локальность является самой сутью пространства, свойством физического мира, то отсутствие локальности, то есть нелокальность, является проявлением свойства мира квантового.

О том, что при рассмотрении проблемы на более глубоком уровне место и расстояние могут утратить свою значимость для понимания общества, утверждал Массер Джордж, опираясь на положения квантовой механики [8]. С точки зрения физики сущность локальности может расширяться в неустановленных пределах, а точнее, меркнет перед установленной скоростью возможной коммуникации, в том числе, между живыми объектами. Нелокальность начинает проявляться повсюду: «Объекты могут обгонять свет; причина и следствие могут меняться местами; расстояние может терять свой смысл; два объекта могут на самом деле быть одним. Вселенная становится пугающей» [8].

Стоит заменить «объект» на сообщество, мы тут же понимаем, что расстояние уже потеряло свой смысл, а два объекта-сообщества на проверку могут оказаться одними и теми же. То есть члены сообщества в том и другом случае могут быть идентичны, хотя и названы по-разному. При непосредственных встречах офлайн их коммуникация и взаимопонимание может осуществляться бессловесно: без помощи любых посредников, путем непосредственного сердечного постижения другого. С открытием Энштейном свойства нелокальности, и в самой возможности взаимодействия между частицами, имеющими определенную связь, которую можно трактовать как «запутанность» (entanglement. - англ.) в квантовой физике, вполне можно пересмотреть и смысл исчезновения локальности в социальных процессах.

Российский философ В.Г. Миронов видел в проблеме локальности и не локальности онтологическую проблему. Для её решения он исследовал возможность переноса свойств квантового мира для понимания философских проблем и взаимоотношений в обществе:
«Проблема локальности и нелокальности социальных явлений перерастает в проблему соотношения локальных и нелокальных связей в универсуме, которая может быть понята как проблема многомерности бытия явлений» [9].

С другой стороны, в попытках приблизиться к пониманию нелокальности, ряд ученых рассматривают в самом устройстве человека квантовую составляющую. Согласно гипотезе Е. Либермана «Человеческое бессознательное и, в частности, бессознательное коллективное в преобладающей степени устроено как система своего рода квантовых биокомпьютеров» [2]. Положение самого локального сообщества периода постиндустриализма можно сравнить с характеристиками квантовомеханического явления запутанности, где квантовые состояния двух или большего числа объектов оказываются взаимозависимыми, и остаются действенными при беспредельном изменении дистанции, в чем видится логическое противоречие с принципом локальности. Это подтверждается и мнением французского философа, признанного исследователя сообществ Ж.-Л. Нанси; «сообщество - это «мы», свершающееся как бытие-вместе другости» [10].

Таким образом, если опираться на редукционистскую методологию, мы видим одномерное линейное представление действительности, в которой сообщества имеют характеристику локальности. При демонтаже локализации как устоявшейся одномерной метрики и локальность и нелокальность предстают выражением «многомерности пространственно-временных структур, несомых ими и сотворяемых ими же в процессах взаимодействия», - считал Миронов, - при этом «в самом факте перехода заключена нелокальность события как реализуемой возможности “быть в ином качестве"», что так же соответствует пониманию сообществ у Нанси.

Для понимания перехода локальных сообществ во внелокальную плоскость ещё раз перечислим все отклонения от генеральной оси локальности, существовавшей прежде, в доинформационную эпоху: пространственная координата уходит на второй план, уступая времени, действию; места трансформируются в потоки, взаимодействие строится по типу сети, сохраняя структуру при увеличении пространственной протяженности; коммуникация между членами сообществ переходит в том числе в виртуальное пространство, где так же начинает происходить процесс зарождения сообществ.

Все это убедительно показывает, как привычные для исследователя трактовки локальных сообществ теряют свое определение, становясь сетевыми, деятельностными, и в целом другими. Необходимо признать, если объект уже становится пространственно дисперсионным, нужно другое определительное, чтобы в нем учитывались происходящие трансформации. В резуль- 
тате было бы оптимальным включить в определение свойство нелокальности, которое объединило все изменения. Но поскольку нелокальность как понятие уже имеет своё устойчивое определение в квантовой физике, и означает наличие информации о всей системе в каждом её компоненте, возможно в социальных науках обозначить утрату локальности сообществами, а также их расширение в пространство виртуальное, другим термином. В новой постиндустриальной, информационной эпохе уместно было бы обозначить такую трансформацию в самом определении сообщества через а-локальность, либо дислокальность. Если алокальность будет обозначать отрицание локальности, в том числе через её расширение и переход в другое пространство, то термин дислокальность, например, в этнографии означает проживание супругов каждый в своём месте. По сути, последний термин для обозначения сообществ периода постиндустриализма так же уместен, по аналогии с браком, как союзом двоих; но в сообществе не два, но более членов связаны воедино в одну структуру, их местоположение может быть различно, а связь осуществляется через удаленный доступ. Таким образом, термин дислокальное сообщество периода постиндустриализма вберет в себя изменчивость локальности, и тем самым, несет в себе более точное определение, а также вмещает в себя все последствия, могущие происходить от такой расширенной пространственности.

\section{ЛИТЕРАТУРА}

1. Вахштайн В. К концептуализации сообщества: еще раз о резидентности или работа над ошибками // Социология власти. - 2013. - № 3. - С. 8-26.

2. Данилевский И.В. Структуры коллективного бессознательного в контексте универсальных гиперболических распределений // Учен. зап. Казан. ун-та. Сер. Гуманит. науки. 2007. №5. URL: https://cyberleninka.ru/article/n/struktury-kollektivnogo-bessoznatelnogo-v-kontekste-universalnyh-giperbolicheskihraspredeleniy (дата обращения: 10.09.2020).

3. Кастельс М. Галактика Интернет: Размышления об Интернете, бизнесе и обществе (англ) русск. / Пер. с англ. А. Матвеева под ред. В. Харитонова. — Екатеринбург: У-Фактория (при участии Гуманитарного ун-та), 2004. — 328 с. (Серия «Академический бестселлер»). Гл. IV - Виртуальные со0бщества или сетевое общество?

4. Кемеров В.Е. Тема сообщества в динамике современной философии // Герменевтика сообщества: материалы конференции / С.И. Голенков (отв. ред.) [и др.]. - Самара: Изд-во «Самарский университет», 2011. - С.8-16

5. Керимов Т.Х. Сообщества: методологические условия описания // С.И. Голенков (отв. ред.) [и др.]. - Самара: Изд-во «Самарский университет», 2011. C.16-27

6. Латур, Б. Пересборка социального: введение в акторно-сетевую теорию [Текст] / пер. с англ. И. Полонской; под ред. С. Гавриленко; Нац. исслед. ун-т «Высшая школа экономики». - М.: Изд. дом Высшей школы экономики, 2014. - 384 с.

7. Лебедева Е. В. «Третье место» как основа формирования городских сообществ. - 2015. - c.52-61 http://elib.bsu.by/bitstream/123456789/122532/1//eбедева_Псков.pdf

8. Массер Дж. Нелокальность. / Пер. с англ. В. Ионов, М. Томс. 000 «Альпина нон-фикшн», 2018. - 108 с. Эл.pecypc: https://read-book-online.com/ fizika/364235-nelokalnost.html?page=1 (дата обращения: 15.11.2020).

9. Миронов Г.Ф. Соотношение локальности и нелокальности научной деятельности в системообразующих связях социума. Социальная жизнь в свете философской рефлексии : сборник научных трудов Третьей международной теоретико-практической конференции, посвященной памяти доктора философских наук, профессора Г.Ф. Миронова, г. Ульяновск, 14-15 мая 2012 г. / под ред. Т.Н. Брысиной. - Ульяновск : УлГТУ, 2012. - 345 с.

10. Нанси Ж.Л. Непроизводимое сообщество: Новое издание, пересмотренное и дополненное / Пер. с франц. Ж. Горбылевой и Е. Троицкого. - М.: Водолей, 2011.- C. 188.

11. Ореховская Е.В., Сыров В.Н. Трансформация определения термина «локальное сообщество» // Фундаментальные научные исследования: теоретические и практические аспекты : сб. материалов IV Междунар. науч.-практ. конф. Кемерово, 31 мая 2017 года. Кемерово, 2017. Т. 2. - C.88-93.

12. Самченко В.Н. Нелокальная связь: философия, математика, физика // Credo New. 2011 - №3. Эл. ресурс: http://www.intelros.ru/readroom/credo_new/ credo-new-3-2011/11060-nelokalnaya-svyaz-filosofiya-matematika-fizika.html (дата обращения: 15.11.2020).

13. Скуратов А.Б. Локальные интернет-сообщества как новый социальный феномен [Электронный ресурс] // Дискурс-Пи. 2010. №1-2. - С.48-53. Электрон. версия печат. публ. URL: https://cyberleninka.ru/article/n/lokalnye-internet-soobschestva-kak-novyy-sotsialnyy-fenomen (дата 0бращения: 08.11.2020).

14. Тыканова Е.В., Хохлова А.М. Траектории самоорганизации локальных сообществ в ситуациях оспаривания городского пространства. // Социология власти. 2014. № 2. - C.104-122

15. Minar D., Greer S. The Concept of Community: Readings with Interpretations (Aldine, Chicago), 1969

16. Relph T. Place and placelessness. -London: Pion Itd, 1976.

17. Samer Faraj, Georg von Krogh, Eric Monteiro, Karim R. Lakhani (2016) Special Section Introduction—Online Community as Space for Knowledge Flows. Information Systems Research 27(4): c. 670 URL: https://doi.org/10.1287/isre.2016.0682

18. Van Dijk J. The network society. London, 2011.

○ Ореховская Евгения Владимировна (yamantaka.j@yandex.ru).

Журнал «Современная наука: актуальные проблемы теории и практики» 